\title{
Educação ambiental:
}

\author{
Entre a intenção e a ação
}

\author{
Sérvio Túlio Portela ${ }^{1}$ \\ Francisco de Assis Braga \\ Helena Alvim Ameno
}

\begin{abstract}
RESUMO: O presente trabalho tem por objetivo apresentar resultados de investigação sobre as percepções de meio ambiente e educação ambiental de professores. Partese do pressuposto de que meio ambiente e educação ambiental extrapolam o contorno meramente biológico ou naturalista, para se revelarem imbricados com dimensões históricas, sociais, culturais e políticas. Realiza-se análise qualitativa de 25 entrevistas semi-estruturadas em cinco escolas estaduais de ensino médio, considerando-se as categorias convencional e transformadora de educação ambiental, e as visões naturalista, globalizante e antropocêntrica de meio ambiente",
\end{abstract}

Palavras-chave: Meio ambiente; educação ambiental; prática docente.

\section{INTRODUÇÃO}

A relação entre homem e natureza, inicialmente de coexistência, foi paulatinamente se convertendo em dominação, onde "o homem serve-se dela, apresenta-a como beleza natural, utiliza-se dela, domina-a e a explora incondicionalmente, sem reservas, sem pudores, sem consciência do futuro". (BRANCO, 2003, p.8)

Dessa relação emergem conceitos de meio ambiente que são emblemáticos quanto a revelar o lugar em que o ser humano se coloca no cenário ambiental. Reigota (1999) categoriza meio ambiente em três visões: naturalista, globalizante e antropocêntrica como sinônimo de natureza intocada, evidenciando somente os aspectos naturais; como relação recíproca entre natureza e sociedade; ou na visão utilitarista de recursos naturais.

Por outro lado, meio ambiente pode ser conceituado como:

\footnotetext{
"um lugar determinado e/ou percebido onde estão em relações dinâmicas e em constante interação os aspectos naturais e sociais. Essas relações acarretam processos de criação cultural e tecnológica e processos históricos e políticos de transformação da natureza e da sociedade" (REIGOTA, 2001, p.21).
}

Para o autor, a superação das perspectivas que inviabilizam reconhecer a relação homem e natureza é possível a partir da dialética que ressitue essas categorias e, com isso, a sua relação, de modo que o ser humano se veja na natureza "sem submeter-se a ela, sem diferenciar-se dela, mas diferenciando-se nela” (PEDROSA, 2007, p.83). Há de se superar os reducionismos e equívocos conceituais que hodiernamente se dão sob a forma de idéias que "exprimem um pensamento antropocêntrico, mais brando, chamado antropocentrismo mitigado ou reformado, que incorpora a preocupação com o direito das gerações futuras" (BRAGA; PAULA, 2007, p. 302). Em suma, para além das dicotomias e do antropocentrismo, outros paradigmas terão de se fazer presentes, de modo que o ser humano se reconheça no meio ambiente que, em última análise, ele compõe, conforma e transforma. 
Essa reorientação de paradigmas não se pode dar de forma espontaneísta, devendo ser provocada por ações e processos eivados de intencionalidade, fato que confere relevância à educação ambiental.

"A educação ambiental deve ser entendida como educação política, no sentido de que ela reivindica e prepara os cidadãos para exigir justiça social, cidadania nacional e planetária, autogestão e ética nas relações sociais e com a natureza." (REIGOTA, 2001, p.10). Pensar e fazer em educação ambiental tem alimentado historicamente a dicotômica relação entre práticas convencional e transformadora (LOUREIRO, 2004).

A educação ambiental convencional tende a ser descolada ou pouco articulada com a ação coletivizadora e engajada nos processos de transformação, buscando, não raro, a disciplinarização e o enfoque biologizante do tema. Diferentemente disso, a orientação transformadora se processa, na perspectiva cidadã, de forma participativa. Por fim, na perspectiva política, enquanto a primeira esvazia de seu conteúdo social e político as abordagens; a segunda volta-se para o trato das práticas sociais e para possibilidade de romper com aquelas que se contraponham ao bem-estar público e às relações de igualdade e de solidariedade.

\section{EDUCAÇÃO AMBIENTAL NA PERSPECTIVA DOCENTE: entre falas e silêncios}

O trabalho investigativo foi desenvolvido com 25 professores das cinco escolasreferência estaduais de ensino médio de Divinópolis-MG. Nas falas e omissões (ou silêncios), captaram-se as suas percepções acerca da educação ambiental, imbricadas com suas próprias concepções sobre meio ambiente. As entrevistas semi-estruturadas, objetos de análise qualitativa, foram realizadas em consonância com a perspectiva de Minayo (2006), e têm o seu exame de mérito identificado com a orientação adotada por Bardin (1977). Assim é que as falas (e os silêncios) dos entrevistados são examinadas à luz das categorias conceituais de Loureiro (2004), relativamente à educação ambiental convencional e transformadora.

Das 25 entrevistas, representativas de todas as disciplinas do currículo escolar, 24 convergiram para a educação convencional, que, ora decorre de uma visão de meio ambiente como sinônimo de natureza, ora como expressão de meio de sobrevivência humana, com caráter utilitarista, ou ainda, como tudo que existe, numa generalização ou imprecisão incapaz de situar o tema. Muitas dessas percepções falam das dimensões naturais da existência e do meio ambiente e se calam quanto às suas dimensões culturais, históricas, sociais ou políticas.

Assim, concorrem decisivamente para a concepção de uma educação ambiental convencional, descolada ou esvaziada de sua problematização na esfera social e política, fazendo-a adstrita à seara do "natural", com enfoque "biologizante". Vale o registro de excertos de entrevistas, dirigidas a cada professor $(P)$, quanto ao seu entendimento sobre meio ambiente e educação ambiental:

\begin{tabular}{|lll}
\hline Prof. & \multicolumn{1}{c}{ Meio ambiente } & \multicolumn{1}{c}{ Educação ambiental } \\
\hline P1 & $\begin{array}{l}\text { "todo espaço que nós vivemos e relacionamos } \\
\text { com plantas, ar, água [...]" }\end{array}$ & $\begin{array}{l}\text { "cuidado que se tem para com tudo isso, com } \\
\text { esse ambiente que você vive." }\end{array}$ \\
P2 & $\begin{array}{l}\text { "[...] preocupação que nós devemos ter com a } \\
\text { natureza, preservar, conservar [...]" }\end{array}$ & $\begin{array}{l}\text { "orientação de }[\ldots] \text { como preservar a natureza, } \\
\text { pra gente continuar a estar junto com ela." }\end{array}$ \\
P3 & $\begin{array}{l}\text { "respeito que deve haver entre o ser humano "Tá falho. Eu acho que a educação ambiental } \\
\text { com a flora e a fauna do Brasil... nossa } \\
\text { preservação aí para que o homem também } \\
\text { continue a existir." }\end{array}$ & $\begin{array}{l}\text { deveria vir como uma disciplina, a partir daí pra } \\
\text { serabalhada não só como todos fazem dentro }\end{array}$ \\
\hline
\end{tabular}


Os depoimentos, no seu conjunto, expressam uma percepção de educação ambiental inspirada ou identificada com "cuidado" e "preservação" da natureza "para que o homem também continue a existir". Não há referência a condicionantes e ou determinantes culturais, sociais e políticos que perpassam as relações das quais o ser humano é parte no meio ambiente. O que se verifica, de resto, é a despolitização ou a não problematização da questão ambiental.

$\mathrm{Na}$ esteira da educação ambiental de caráter convencional, têm-se ainda percepções que enfatizam sua conotação de espaço que habita o ser humano. Essas percepções revelam uma concepção de meio ambiente que transita entre a visão naturalista e antropocêntrica:

\begin{tabular}{|c|c|c|}
\hline Prof. & Meio ambiente & Educação ambiental \\
\hline P3 & $\begin{array}{l}\text { "tudo que tá em volta da gente - a nossa escola, } \\
\text { nossa casa, onde a gente mora, nosso bairro, } \\
\text { nossa cidade. É onde a gente vive." }\end{array}$ & $\begin{array}{l}\text { "a gente tem que trabalhar com todo mundo, } \\
\text { com a gente mesmo, pra gente trazer a educação, } \\
\text { separar o que é reciclado, o que não é, o que } \\
\text { serve, o que não. Não é isso?" }\end{array}$ \\
\hline P4 & $\begin{array}{l}\text { "tudo aquilo que nos cerca, não só urbano, não } \\
\text { só natureza propriamente dita, a original, mata } \\
\text { virgem no caso, mas é tudo que nos cerca. Ele } \\
\text { pode ser estudado, analisado e é pra nosso bem } \\
\text { conhecê-lo pra que possa melhor preservá-lo e } \\
\text { utilizar dos próprios recursos que ele nos } \\
\text { oferece." }\end{array}$ & $\begin{array}{l}\text { "Educação ambiental é, além desse estudo, né, } \\
\text { dessa análise do que nos cerca, do entorno } \\
\text { nosso, para favorecer a melhor utilização, } \\
\text { preservação. }\end{array}$ \\
\hline
\end{tabular}

Expressões como meio ambiente é "tudo que está em volta da gente", "tudo aquilo que nos cerca" colocam o ser humano no centro da cena ambiental e redundam em percepções da educação ambiental como estratégia para "trazer a educação, separar o que é reciclado, o que não é o que serve, o que não" ou então como meio de educar "para favorecer a melhor utilização, preservação", fazendo emergir a visão preservacionista com caráter utilitarista, igualmente sem incorporar a problematização mais ampla da temática ambiental, traduzindo, em última análise, a ótica convencional da prática educativa.

Sob a égide da concepção conservadora de educação ambiental, revelam-se ainda percepções inspiradas nos paradigmas holonômicos, que ora percebem educação (e meio ambiente) como "tudo" (ou qualquer coisa), ora situam-na com uma conotação universalizante, na imprecisão de conceitos para designá-la. É o que se vê nas falas dos seguintes entrevistados:

\begin{tabular}{|c|c|c|}
\hline Prof. & Meio ambiente & Educação ambiental \\
\hline P5 & $\begin{array}{l}\text { "conjunto de absolutamente } \\
\text { tudo que existe, tudo que existe } \\
\text { é meio ambiente. Então está } \\
\text { inserido no meio ambiente todas } \\
\text { as formas de vida." }\end{array}$ & $\begin{array}{l}\text { "é fazer com que o ser humano, é despertar no aluno mesmo, se } \\
\text { você estiver na sala de aula; se você estiver na rua, na pessoa } \\
\text { com que você encontrou; se você estiver em casa, no seu filho, } \\
\text { nas pessoas com quem convive, despertar nas pessoas a } \\
\text { consciência de que todas as ações dela de consumo, de...., } \\
\text { principalmente de consumo, porque consumo fecha tudo, esta } \\
\text { interferindo direta ou indiretamente com o conjunto de todas as } \\
\text { espécies vivas e de todas as coisas que existem, tá, no planeta } \\
\text { inteiro, e até alguma coisa fora dele, porque ele está dentro de } \\
\text { um sistema maior, que é o sistema solar." }\end{array}$ \\
\hline P6 & $\begin{array}{l}\text { "engloba tudo, o mundo inteiro, } \\
\text { e meio ambiente é a } \\
\text { preocupação que nós devemos } \\
\text { ter com a natureza, preservar, } \\
\text { conservar" }\end{array}$ & $\begin{array}{l}\text { "é uma orientação de como cuidar da nossa casa, como preservar } \\
\text { a natureza, pra gente continuar a estar junto com ela." }\end{array}$ \\
\hline
\end{tabular}

Por outro lado, somente um dos entrevistados revelou na sua percepção flagrante inclinação transformadora. Essa categoria privilegia a idéia de situação dos indivíduos nas suas relações com o coletivo, na perspectiva de politização e publicização da problemática ambiental, que suscita a participação e o exercício da cidadania, acenando com a possibilidade de romper com práticas sociais contrárias ao bem-estar público, à equidade 
e à solidariedade, a partir de mudanças nos referenciais éticos dos sujeitos sociais. Vale reproduzir trechos da entrevista:

\begin{tabular}{|c|c|c|}
\hline Prof. & Meio ambiente & Educação ambiental \\
\hline $\mathbf{P} 7$ & $\begin{array}{l}\text { "numa visão clássica, } \\
\text { seria tudo que nos cerca e } \\
\text { inclui nós mesmos, de } \\
\text { alguma forma. Meio } \\
\text { ambiente, na verdade, ele } \\
\text { não é uma coisa exterior } \\
\text { a nós, inclusive eu até } \\
\text { hoje não entendo porque } \\
\text { que chama meio, não sei } \\
\text { se é meio de subsistência, } \\
\text { meio ambiente, alguma } \\
\text { coisa assim. Agora, é } \\
\text { isso, eu acho que é um } \\
\text { meio de sobrevivência, } \\
\text { não só de sobrevivência, } \\
\text { se não a gente fica... não } \\
\text { sei se é meio de } \\
\text { subsistência, ra meio } \\
\text { ambiente, alguma coisa } \\
\text { assim, mas é o espaço de } \\
\text { convivência, é um espaço } \\
\text { de interação entre a gente } \\
\text { e as outras manifestações } \\
\text { de vida." }\end{array}$ & $\begin{array}{l}\text { "num primeiro momento educação ambiental, ou seja, atualmente } \\
\text { corresponde, assim, é..., há grande ênfase nessa capacidade da gente } \\
\text { conviver ou não com a natureza, com o planeta Terra, com as outras } \\
\text { pessoas, não só uma ênfase, como uma necessidade, o sinal disparou, o } \\
\text { alarme disparou. Ou nós cuidamos dele, e de nós mesmos, } \\
\text { conseqüentemente de nós mesmos, ou a gente está fadado ao fracasso, } \\
\text { né. Agora o que eu acho interessante na educação ambiental é que eu } \\
\text { acho que mudanças significativas estão acontecendo... Isso é um } \\
\text { processo, as pessoas estão aprendendo, muita gente faz do mundo uma } \\
\text { lata de lixo, mas as pessoas, o grande problema é o tempo que nós } \\
\text { temos pra aprender isso, que é extremamente curto, mas eu acho que } \\
\text { tem havido um avanço significativo, sim. Agora eu acho que é } \\
\text { importante colocar o seguinte, pode parecer uma atitude assim muito } \\
\text { personalista assim, mas eu acho que tem que descobrir as pessoas que } \\
\text { de fato poluem, entendeu, as pessoas que de fato, eu sei que isso que eu } \\
\text { vou falar pode ser mal interpretado, mas, por exemplo: concretamente, } \\
\text { você tem as propagandas lá ensinando o pobre na hora que estiver } \\
\text { escovando os dentes fechar a torneirinha, eu não vejo uma propaganda } \\
\text { ensinando o rico a esvaziar a piscina dele e parar de encher de milhões } \\
\text { de litros de água, eu acho assim que os grandes responsáveis ainda pela } \\
\text { degradação do meio ambiente, são aqueles que detêm as suas riquezas, } \\
\text { fábricas, usinas, eu acho que, eu não vejo assim a população no geral } \\
\text { como a primeira inimiga, né, do meio ambiente. É claro que ela precisa } \\
\text { passar por esse processo de reeducação, mas eu vejo uma } \\
\text { responsabilidade muito grande dos empresários e etc., e eu não vejo } \\
\text { isso tão vinculado assim às campanhas, à televisão, à mídia de forma } \\
\text { geral, não.." }\end{array}$ \\
\hline
\end{tabular}

O entrevistado, ao mesmo tempo em que repele a idéia de espaço físico, de abrigo ou casa em que habita a humanidade, tenta empreender uma reflexão sobre o vocábulo "meio" (não sei se é meio de subsistência, meio ambiente, alguma coisa assim...), para concluir que meio ambiente "é o espaço de convivência, é um espaço de interação entre a gente e as outras manifestações de vida." Essa concepção coloca, para além da visão utilitarista da "casa" e da concepção antropocêntrica da cena ambiental, a percepção do locus das múltiplas interações, em meio às quais o ser humano constitui mais um dos atores, sem assumir o protagonismo da existência, o centro do universo.

Dessa percepção, o entrevistado se permite problematizar a temática ambiental, cujo tratamento ele reconhece "como uma necessidade, o sinal disparou, o alarme disparou, ou nós cuidamos dele, e de nós mesmos, conseqüentemente de nós mesmos, ou a gente está fadado ao fracasso". Assim, registra a necessidade de mudança de atitude, mas amplia a percepção das responsabilidades, ao citar que as campanhas educativas se dirigem ao pobre na recomendação de "fechar a torneirinha", enquanto passam ao largo da responsabilidade dos cidadãos ricos e dos empresários (e suas empresas), cujas ações (e omissões) não se fazem tema "tão vinculado assim às campanhas, à televisão, à mídia de forma geral, não." Nessa ponderação, faz-se presente a alusão às responsabilidades sociais, à cidadania, à (des) igualdade social.

Em última análise, a presente entrevista deixa entrever uma flagrante inclinação a comprometer a temática e à educação ambiental propriamente dita com as relações ente o individual e o coletivo, politizando e publicizando as questões pertinentes, na direção da prática cidadã que se permita romper com as práticas sociais contrárias ao bem-estar público, à eqüidade e à solidariedade. 


\section{CONSIDERAÇÕES FINAIS}

A crise ambiental sem precedentes, instaurada historicamente pela intervenção do homem como expressão de seus valores, conceitos e ações nas relações que estabeleceu com o ambiente de que é parte integrante, requer reorientação de conduta cuja efetivação reclama prática educativa eficaz, de cunho transformador.

Dada a missão que assume a educação face o desafio em tela, em particular a educação ambiental, há de se ter deliberada intencionalidade perpassando o pensar e o fazer nessa seara. Assim é que se faz necessário estabelecer clara orientação conceitual acerca de meio ambiente e inequívoca orientação metodológica e político-pedagógica para levar a termo a práxis educativa.

Nesse sentido, superar as concepções reducionistas acerca de meio ambiente, que o traduzem como o meio natural do qual o ser humano se utiliza, numa ótica antropocêntrica e ou utilitarista é um imperativo. Reconhecer-se como parte constitutiva desse cenário, no âmbito do qual se estabelecem relações mediadas por fatores naturais, sociais, históricos e políticos, dentre outros, é também imprescindível.

Sob tais concepções, há de se tratar a educação lato sensu como um complexo de teorias e práticas cuja intencionalidade se deve comprometer com a (trans)formação do ser humano, que se há de redimensionar como sujeito social, na perspectiva cidadã. Nessa linha, a educação ambiental não se pode traduzir na ótica convencional, que, biologizando o tema meio ambiente, tende a reduzi-lo a espaço natural e ou a esvaziá-lo de suas dimensões históricas, culturais, sociais, políticas etc. Diferentemente disso, há de se comprometer com a ótica transformadora, apreendendo e problematizando a realidade, nas suas múltiplas facetas e relações.

Todavia, para levar a efeito esse mister, há de superar as disciplinarizações inspiradas na ótica racionalista, assim como as dicotomizações homem $x$ ambiente, natureza x cultura, certeza $\mathrm{x}$ incerteza.

A superação dos reducionismos e equívocos conceituais passa inevitavelmente pelo (re) conhecimento das percepções docentes acerca de educação ambiental (e meio ambiente). Afinal diagnosticar o quadro que se desenha quanto à práxis educativa em curso e reorientar as políticas públicas de formação inicial e continuada de professores é imprescindível para que se possa extrapolar do limite da intenção para a ação.

No caso em tela, o pensar e o fazer em educação ambiental revelou flagrante predomínio da orientação conservadora na percepção docente quanto à educação ambiental, o que aponta para a necessidade de se ampliar o diagnóstico e assumir o mister de adoção de políticas efetivas e eficazes na seara da educação ambiental que lhe possam ensejar reorientação identificada com a ótica transformadora, sob pena de não se reverter o quadro de crise ambiental (e de paradigmas) que se tem na contemporaneidade.

\section{REFERÊNCIAS}

BARDIN, L. Análise de conteúdo. Tradução Luís Antero Reto e Augusto Pinheiro. Lisboa: Edições 70, 1977. 229 p.

BRAGA, F. A.; PAULA, L. I. O meio ambiente na perspectiva cultural contemporânea do Direito no Brasil. In: De Jure - Revista Jurídica do Ministério Público de Minas Gerais. Belo Horizonte: Ministério Público de Minas Gerais, n. 9., jul./dez. 2007. p. 299 - 321.

BRANCO, S. Educação ambiental: metodologia e prática de ensino. Rio de Janeiro: Dunya, 2003. $80 \mathrm{p}$.

LOUREIRO, C. F. B. Educação ambiental transformadora. In: BRASIL, Ministério do Meio Ambiente. Diretoria de Educação Ambiental. Identidades da educação ambiental brasileira. Brasília: Ministério do Meio Ambiente, 2004. p. 65 - 84. 
MINAYO, M. C. S. Trabalho de campo: contexto de observação, interação e descoberta. In: . Pesquisa Social: teoria, método e criatividade. 25.ed. Petrópolis: Vozes, 2006, cap. 3, p.61-77.

PEDROSA, J. G. O capital e a natureza no pensamento crítico. In: LOUREIRO, C. F. B. (Org.) A questão ambiental no pensamento crítico; natureza, trabalho e educação. Rio de Janeiro: Quartet, 2007. p. 69 - 112.

REIGOTA, M. Ecologia, elites e intelligentsia na América Latina: um estudo de suas representações sociais. São Paulo: Annablume, 1999. 115 p.

O que é educação ambiental. 1. ed. 3. reimp. São Paulo: Brasiliense, 2001. 62

p.

1 Aluno e professores, respectivamente, do Programa de Mestrado em Educação, Cultura e Organizações Sociais da Universidade do Estado de Minas Gerais - Campus da Fundação Educacional de Divinópolis. 